\title{
Rural Income Volatility and Inequality in China ${ }^{1}$
}

\author{
John Whalley \\ University of Western Ontario (UWO) \\ CIGI and NBER
}

Ximing Yue

The Institute of Economics Chinese Academy of Social Sciences (CASS)

And UWO

April 2006

\footnotetext{
${ }^{1}$ We are grateful to Jim Davies and Terry Sicular for suggestions and discussion. Ximing Yue wants to thank Ford Foundation Beijing Office for support a year stay in at the University of Western Ontario during which this research is carried out.
} 


\begin{abstract}
:
Much of current poverty debate in China focuses on the growing urban-rural income gap (the ratio of mean urban to rural incomes). Available data indicates a significant increase from around 1.8 in the late 1980's to over 3 today, but these estimates do not take into account the higher volatility of rural incomes in China. Current literature based analyses of rural income volatility decompose poverty into chronic and transient components using longitudinal survey data and assesses the fraction of the Foster, Greer and Thorbecke poverty gap which is attributable to mean income over time being below the poverty line. Resulting estimates of $40-50 \%$ transient poverty point to the policy conclusion that poverty may be a less serious social problem than it appears in annual data due to rural income volatility. Here we use a direct method to adjust rural income for volatility using a certainty equivalent income measure and recomputed the urban-rural income gap. Since an uncertain income stream is worth less in utility terms than a certain income stream we argue that heightened rural volatility increases the effective urbanrural income gap and intensifies not weakens poverty concerns. Using Chinese longitudinal rural survey data for which current decompositions can be replicated, we make adjustments for certainty equivalence of rural household income streams which not only widen the urban-rural income gap in China but also increases other distributional summary statistics. Depending upon values used for the coefficient of relative risk aversion, the measured urban-rural income gap increases by 20 - 30\% using a certainty equivalent measure to adjust rural incomes for volatility.
\end{abstract}




\section{Introduction}

There has been substantial debate inside and outside China on growing relative poverty (on inequality) as an accompaniment to China's high growth. While absolute poverty in terms of number of individuals in households below any given poverty line has fallen in recent years, relative income measures have widened. Li and Yue (2004) using Chinese survey data suggest that the urban-rural income gap (the ratio of mean urban and rural incomes) may have increased from around 1.8 in the late 1980’s to around 3 today. It is widely acknowledged that a variety of factors currently unaccounted for may further widen this gap, such as differential availability of education and health care. The factor we focus on here is the substantially higher volatility of Chinese rural as compared to urban incomes.

Recent literature on transient and chronic poverty (Jalan and Ravallion, 1998 (JR); Li, Wang and Yue, 2005) discuses rural income volatility in China in terms of the relative size of these two components rather than the direct adjustment that needs to be made to distributional summary statistics for income (or consumption) volatility. JR use Chinese longitudinal data and estimate that $49 \%$ of poverty in their sample is transient, where transient poverty is defined as the portion of the Foster, Greer and Thorbecke (FGT) squared poverty gap which is removed by using mean income over the sample period to measure the gap. This finding suggests that if poor households have access to capital markets which allow them to income smooth across time, poverty should perhaps be regarded as a less serious social problem in China (and perhaps elsewhere) than currently.

If the alternative (and seemingly more realistic) assumption is made that poor households in villages have either no access to capital markets, or access only at 
prohibitively high borrowing rates, the issue instead is how to take rural income (or consumption) volatility into account when constructing measures of income (or consumption) inequality. We use a utility of income function which is of iso-elastic form (constant relative risk aversion CRRA), and longitudinal data for rural households to construct measures of certainty equivalent income or consumption (equivalent in expected utility terms) for rural incomes. We then calculate summary distributional measures for China including both the urban-rural income gap and the Gini coefficient for both certainty equivalent income (consumption) and observed income and compare them. Data only allow us to adjust rural incomes in this way, but it is in the rural sector in China that volatility is most pronounced.

Our results indicate that both the urban-rural income gap and other measures of inequality in China need to be revised upwards and by perhaps 20 - 30 percent in the case of the urban-rural income gap. Smaller but still significant modifications to Gini coefficients also result. The size of revisions depends on the value used for the coefficient of relative risk aversion. In our analysis, volatility of rural incomes reduces their certainty equivalent value relative to observed income and significantly worsens rather than ameliorates relative poverty in China. 


\section{Chronic and transient poverty measures and the certainty equivalent income approach to adjusting income (consumption) for volatility.}

A major theme in recent poverty research on China has been to distinguish between transient and chronic poverty. Jalan and Ravallion (1998) measures these two components of poverty in China using longitudinal rural household survey data. Their chronic poverty measure captures the component of poverty attributable to the mean income level of households over time. Their transient measure of poverty is the difference between a total poverty measure and its chronic component. Significant transient relative to chronic poverty suggests that poverty may be less serious when viewed as a long term problem, and distributional concerns in policy implementation should perhaps receive a lower weight.

In JR the mean income level used to measure chronic poverty is the time mean of household income over the period at issue. ${ }^{2}$ This implicitly assumes that households can borrow and lend during the period at the same interest rate. Use the squared poverty gap (SPG) index proposed by Foster et al. (1984), the aggregate poverty measure over time and its two JR components for a total population can be expressed as:

$$
\begin{aligned}
& A(T)=\frac{1}{T N} \sum_{t=1}^{T} \sum_{i=1}^{N} g\left(y_{i t}\right)^{2} \\
& C(T)=\frac{1}{N} \sum_{i=1}^{N} g\left(\bar{y}_{i}\right)^{2} \\
& T(T)=A(T)-C(T)
\end{aligned}
$$

\footnotetext{
2 Rodgers and Rodgers (1993) measure constant income over time as 'permanent income'; the maximum annual consumption level that an agent could achieve from his or her actual income stream over the same period. (Rodgers and Rodgers, 1993, p. 31.) Permanent income is the time mean of individual income if one assumes that interest rates for borrowing and lending are the same. Rodgers and Rodgers (1993) also discuss the case where borrowing and lending rates differ.
} 
where $A(T), C(T)$ and $T(T)$ are aggregate poverty indices over time, the chronic poverty index and the transient poverty index respectively. $T$ and $N$ stand for the number of years and the number of individuals in the sample. ${ }^{3} g\left(y_{i t}\right)$ is the FGT poverty gap measure for individual $i$ at the time $t$ and is defined as $g\left(y_{i t}\right)=\left(1-\frac{y_{i t}}{z}\right)$ when $y_{i t}<z$ and $g\left(y_{i t}\right)=0$ if $y_{i t} \geq z . z$ represents a predetermined poverty line. $g\left(\bar{y}_{i}\right)$ has a similar meaning to $g\left(y_{i t}\right)$, but is defined over the time mean of individual income, $\bar{y}_{i}=\frac{1}{T} \sum_{t=1}^{T} y_{i t}$, rather than individual income at time $t$ (denoted by $y_{i t}$ ).

Transient poverty in JR is interpreted by substituting (1) and (2) into (3) and rearranging to yield,

$$
T(T)=\frac{1}{T} \sum_{t=1}^{T}\left(\frac{1}{N} \sum_{i=1}^{N} g\left(y_{i t}\right)^{2}-\frac{1}{N} \sum_{i=1}^{N} g\left(\bar{y}_{i}\right)^{2}\right)
$$

The term inside the large bracket on the right hand side of (4) is the difference between the annual poverty index and the chronic poverty index in year $t$, and its value can be either positive or negative. A positive value implies that some poverty experienced in year $t$ is not chronic, while a negative value indicates that chronic poverty is temporarily absent in year $t$. Transient poverty over the time period of observation is simply a time mean of the difference in each year from the mean. ${ }^{4}$

This approach to poverty measurement aims to provide an assessment of the relative importance of chronic and transient poverty. It can be also interpreted as providing a

\footnotetext{
${ }^{3}$ We assume here that every household in the sample is present through all the observed years. Rodgers and Rodgers (1993) discuss the case where some individuals may be observed only for part of the whole period under survey due to birth, death, migration and other factors.

${ }^{4}$ The intuition behind this transient poverty measure is also clear from the term inside the large bracket on the right hand side of equation (4), $g\left(y_{i t}\right)-g\left(\bar{y}_{i}\right)$. For an individual with $g\left(y_{i t}\right)>0$ and $g\left(\bar{y}_{i}\right)=0$, the poverty that the individual experienced in the year is wholly temporarily, and chronic poverty is zero.
} 
framework for investigating the effects of income volatility or income uncertainty on poverty. ${ }^{5}$ Heightened income variation over time will tend to increase transient poverty, and hence inter-temporal aggregate poverty, unless income is maintained above the poverty line throughout the whole period of observation.

Direct adjustment of income for volatility has been overlooked thus far in the poverty debate in China. If rural incomes are considerably more volatile than urban incomes, as is true today in China volatility should worsen the relative poverty picture, not ameliorate it as results from existing chronic-transient decomposition implicitly suggest. Higher rural volatility reflects weather and other features which urban residents do not face. This difference in income volatility between urban and rural residents has implications for both the size of urban-rural income gap and for other distributional summary statistics, such as the Gini coefficient.

Per capita incomes of urban residents in China have been rising for the past two decades and with no adjustment for volatility the urban-rural income gap was 3.2 in 2002, one of the highest in the world. ${ }^{6}$ The income definition underlying these estimates (and used by the National Bureau of Statistics of China (NBS)) does not capture subsidies to education and health care from various levels of government, security insurance, pensions and other features. ${ }^{7}$ These subsidies mostly accrue to urban residents and an urban-rural income gap capturing these is also likely to be higher.

\footnotetext{
${ }^{5}$ See also the discussion in Ravallion (1988) where the argument is also made that income risk affects poverty.

${ }^{6}$ See Knight and Song (1999).

${ }^{7}$ Besides disparity in the public services as well as income volatility between urban and rural, urban-rural difference in the cost of living is a further factor that potentially affects the urban-rural income and overall inequality in China but is ignored thus far. Unlike public services and income volatility, the gap in the cost of living between urban and rural sector will bias the urban-rural gap downwards if it fails to taken into accounts, as the cost of living tends to be higher in urban than in rural. Sicular et al. (2005) attempts to measure urban-rural income gap and overall inequality by controlling for gap in the cost of living between urban and rural and finds substantial decline in estimated urban-rural income ratio, from 3.39 to 2.38 in 2002.
} 
Estimates of inequality using certainty equivalent income to adjust for volatility of incomes allow us to re-assess relative inequality for a population where incomes are certain for one part of the population but uncertain for another. Inequality is underestimated for the population if one fails to take into account income or consumption risk.

Since uncertainty of income reduces individual welfare when expressed in terms of expected utility relative to a constant and certain income, we adjust observed rural incomes to account for volatility using the certainty equivalence of an income (consumption) stream. We take as given an individual utility of income (or consumption) function, $U(y)\left(U^{\prime}(y)>0, U^{\prime \prime}(y)<0\right)$, and an income stream for a household over a period of observation, $y_{i 1}, y_{i 2}, \ldots, y_{i T}$. Given the concavity of $U(y)$,

$$
U\left(\bar{y}_{i}\right)>\sum_{t=1}^{T} w_{i t} U\left(y_{i t}\right)
$$

where $\bar{y}_{i}$, mean income of household $i$, is defined as $\bar{y}_{i}=\frac{1}{T} \sum_{t=1}^{T} y_{i t} \cdot w_{i t}\left(\sum_{t=1}^{T} w_{i t}=1\right)$ and the right hand side of (5) includes period weights, representing the probability that income $y_{i t}$ occurs in year $t$. Thus, if there are two households, one receiving a variable income stream $y_{i 1}, y_{i 2}, \ldots, y_{i T}$, and the other receiving an identical amount of income equal to $\bar{y}_{i}$ in each period, the expected utility over the observed period is lower for the household with time-varying income than for the household who receives constant or certain income. 
Equation (5) thus allows us to construct a measure of certainty equivalent income, denoted as $y^{c}$, for any time varying income stream $y_{i 1}, y_{i 2}, \ldots, y_{i T}$. This can be obtained by solving the equation:

$$
U\left(y_{i}^{c}\right)=\sum_{t=1}^{T} w_{i t} U\left(y_{i t}\right)
$$

The concavity of (5) implies that the certainty equivalent income, $y_{i}^{c}$, is smaller than the average of the time-varying income stream $\bar{y}_{i}$. Adjusting rural income for volatility in this way will intensify rather than ameliorate relative urban-rural poverty in China in contrast to the direction that currently available decompositions of poverty into chronic and transient components point.

Using certainty equivalent income measures we can also define an equivalence scale, denoted as $s_{i}$, as the ratio of certainty equivalent income to the time mean of the uncertain income stream. $s_{i}=y_{i}^{c} / \bar{y}_{i}$ has values which lie between 0 and 1, i.e. $0<s_{i} \leq 1$. $s_{i}=1$ implies that household $i$ receives constant income throughout the whole period of observation; the more volatile income is the smaller $s_{i}$ is. $s_{i}$ also depends on $y_{i}^{c}$, which in turn depends on the degree of curvature of the utility function; the more concave the utility function, the smaller $y_{i}^{c}$, as well as $s_{i}$.

In the calculations of certainty equivalent rural income for China we report below, we use a utility function with constant relative risk aversion (CRRA) since we want the proportional adjustment to income (or consumption) for certainty equivalence to be unit 
independent. ${ }^{8}$ Using a constant absolute risk aversion utility function does not achieve this result. ${ }^{9}$ We specify preferences as:

$$
u(c)=\frac{c^{1-\gamma}}{1-\gamma}
$$

where $c$ can denote either income or consumption. The Arrow-Pratt measure of constant relative risk aversion for these preferences is given by:

$$
\gamma=-\frac{u^{\prime \prime}(c) c}{u^{\prime}(c)}
$$

$s_{i}$ and $\gamma$ are negatively related, i.e. a larger $\gamma$ yields a more concave utility function, leading to a lower value of $s_{i}$.

Both the equivalence scale and the size of certainty equivalent income depend on the values of the coefficient of risk aversion, $\gamma$. There has been a large body of literature on estimates of risk aversion with widely dispersed results. Using labor supply data recent work of Chetty (2006) gives estimates of $\gamma$ around 1, while earlier studies using data on insurance produce estimate of $\gamma$ ranging from 2 to $10 .{ }^{10}$ Literature on risk aversion in developing economics suggests moderate risk aversion, with a coefficient of risk aversion ranging from 1 to 2. Alderman and Paxson (1994) provides a detailed survey of literature estimates of coefficients of risk aversion in developing countries. We use a number of

\footnotetext{
${ }^{8}$ Priori literature alludes to but it does not explicitly set our the approach we detail here using a CRRA utility function. Morduch (1995) briefly discusses but does not explicitly calculate certainly equivalence income measures for use in distributional statistics, and suggests using a Taylor series expansion of $u(c)$. Newbery and Stiglitz (1981), in discussing commodity price stabilization schemes, suggest calculating the amount the individual will pay to forgo uncertainty, but they do not discuss the application of certainty equivalence calculations to distributional measures.

${ }^{9}$ Constant absolute risk aversion preferences, $u(c)=-1 / \sigma * \exp (-\sigma c)$, or related variants are also less commonly used utility functions.

${ }^{10}$ See Chetty (2003) for brief survey of studies of risk aversion using insurance data and experimental methodology.
} 
hypothesized values of $\gamma$ between 0.9 and 10.0 appealing to literature estimates of $\gamma$ in Chetty (2003), and assess how sensitive $s_{i}$ is to the degree of risk aversion.

We examine the impact of more volatile incomes in rural China on the urban-rural income gap and overall inequality in China by reporting ratios of urban to rural income based on certainty equivalent incomes, as well as a number of inequality indices. Of the inequality indices we report, the Atkinson index is of particular relevance to our certainty equivalent income approach since it deals with the related issue of social inequality aversion and use a similar functional form. This index can be expressed as:

$$
I=1-\frac{y_{\text {ede }}}{\bar{y}}
$$

where $y_{\text {ede }}$, is the equally distributed equivalent income, and defined as that income level which, if equally distributed, would give the same level of social welfare as the existing distribution. The interpretation of Atkinson index is the proportion of total income that would be required to achieve the same level of social welfare if incomes were equally distributed. A value of 0.12 , for instance, means that we could reach the same level of social welfare with only $88(1.00-0.12)$ percent of the present income. ${ }^{11}$ Assuming that each individual has a constant absolute risk aversion utility function given in equation (7) and that total social welfare is sum of individual utilities, the equally distributed equivalent income can be derived as:

$$
y_{\text {ede }}=\left[\sum_{i=1}^{n} Y_{i}^{1-\varepsilon}\right]^{\frac{1}{1-\varepsilon}}
$$

\footnotetext{
${ }^{11}$ See Atkinson (1975) pp. 48-9.
} 
It should be noted that $\varepsilon$ here has different meaning than $\gamma$ in our definition of certainty equivalent income above. In defining certainty equivalent income $\gamma$ captures individual evaluation of income risk, while in the Atkinson index $\varepsilon$ represents the social aversion to inequality. More importantly, $\varepsilon$ represents the weight that society, or an investigator, attach to inequality in the income distribution. $\varepsilon$ takes values of above 0 and a larger value of $\varepsilon$ attaches more weight to lower incomes in the distribution and indicates that society is more concerned over the situation of lower income individuals. The choice of $\varepsilon$ is a matter of subjective judgment and inevitably arbitrary, but 2 is widely used and thought by others to be reasonable and broadly acceptable. ${ }^{12}$ In calculations later using the Atkinson index as a summary measure of the overall distributions after adjustment for certainty equivalence, we use the same values of $\varepsilon$ as we use for $\gamma$ in calculating certainty equivalent income. This allows us to compute total measures of income inequality capturing both social aversion to inequality and volatility of income, and assess each component.

${ }^{12}$ See Anand (1983) p. 84 for further discussion of values for $\gamma$. 


\section{Data used, potential biases, and correction}

The data set we use for the certainty equivalent income adjustments to rural incomes that we make comes from the third round of the Chinese household income surveys (CHIP for short below). This was conducted in 2003 for the reference year 2002, and contains both urban and rural sub-samples, as well as a migrant sample. ${ }^{13}$ Each of the urban and rural samples is nationally representative, and income per capita and Gini coefficients for both urban and rural samples are close to estimates published by Chinese official sources and are based on the same definition of income used by the National Bureau of Statistics (NBS). Combining both urban and rural samples from this data yields estimates of overall inequality that are also nationally representative. ${ }^{14}$ The NBS sample survey data is unfortunately not publicly available.

Data provided by this survey is cross-section and at a household level. Complete information was only collected for households for the single year of 2002; however, for the questions on income, consumption and the number of household, households were also asked in the rural questionnaire to record their income and consumption back to 1998. This yields longitudinal data for these variables from 1998 to 2002 for each household in the rural sample which can be used to adjust rural income (and consumption) for 2002 for certainty equivalence. This is the longitudinal panel data that we use to adjust rural incomes to assess the extent to which income volatility in the rural sector affects the measured urban-rural income gap.

Income and consumption in all household surveys is measured with error. Here the central issue with its reliability is that the measurement of personal income and

\footnotetext{
${ }^{13}$ For details of survey design and other issues in the use of this survey data see Li, et. al (2005).

${ }^{14}$ This is achieved by weighting the urban and rural sample so that the distribution of sample individuals between urban and rural segments equals the urban-rural distribution in the Chinese population.
} 
consumption by respondents is based on recall. The accuracy of reported income may thus be a more serious problem as the date for which the respondents are asked to remember their income recedes from the date at which the survey takes place

Underestimation of income is most likely when collected by recall if there is loss of memory as time pass. Such misestimation will also bias estimates of chronic and transient poverty, because misestimation can lead to a lower time mean of household income. Misestimation of income can also lead to mismeasurement of the variation of household income over time, potentially leading to an upper bias in the estimated certainty income equivalent scale $s_{i}$. Given a predetermined poverty standard chronic poverty may also be underestimated.

Checking income levels and their dispersion for each year in our data relative to corresponding estimates that are published by Chinese official sources for each of the corresponding years serves as a partial source of verification of our data. NBS estimates of income and its distribution are based on annual surveys and are free of memory error which attaches to data generated by recall. The NBS sample, from which the CHIP sample is selected, is large (around 60,000 households every year) and households are sampled using a two stage stratified systematic random sampling scheme. The sampling bias of official estimates of income and its dispersion is thus small.

Table 1 compares income per capita estimates and Gini coefficients between the NBS large sample and the CHIP small sample for the years 1998 through 2002. The average income from the CHIP sample, which is based on recall by respondents, is underestimated by 8.29 percent for 1998 and 4.71 percent for 1999 compared to estimates of income per capita based on the NBS sample. For the other three years, per capita 
incomes based on the CHIP sample are all higher than those from the NBS sample but are close.

The underestimation is larger for consumption per capita. All consumption per capita estimates based on recall from the CHIP sample (for 1998 through 2001) are below those from the NBS sample. Consumption per capita based on the CHIP sample is lower than in the NBS sample by 15.55 percent in 1998 and 11.39 percent in 1999. Unlike income per capita, the dispersion of income measured by Gini coefficients is similar between the two samples. ${ }^{15}$ Underestimation of income in 1998 and 1999 thus appears to be roughly uniform across households surveyed. If the use of recall underestimates income per capita similarly for all households, the Gini coefficient will be unchanged since the Gini coefficient is independent of the unit of income measure used.

Estimates of both transient poverty and certainty equivalent income (or consumption) are thus biased unless underestimation of average income and consumption per capita over time for recall bias is corrected for. We have made a correction for each of the years from 1998 to 2002 in our data by scaling up (if estimates of per capita income based on the CHIP sample are below those from the NBS sample) or down (if estimates of per capita income based on a CHIP sample are above those from the NBS sample) so that mean incomes based on the CHIP sample equal those based on the NBS sample. This scaling has no effect on estimates of Gini coefficients and other measures of inequality which are independent of scale.

\footnotetext{
${ }^{15}$ This comparison is only possible for income, since there are no measures of dispersion of consumption per capita available from official data.
} 


\section{Transient poverty measures and certainty equivalent adjusted income distribution measures}

In the next section we report estimates of the urban-rural income gap and the Gini coefficient and other summary measures of the income distribution for the whole of China based on both observed and certainty equivalent rural incomes. We first, however, report measures of total poverty and its transient and chronic components for our sample data using the JR methodology. We replicate Jalan and Ravallion (1998) and Li, Wang and Yue (2005) using our data set, and first confirm in our data the JR result that transient poverty accounts for a large proportion of total poverty in rural China. Our estimates of decomposed poverty indices from this replication also support the reliability of data used in our study. Since our decomposition estimates are broadly consistent with results from earlier work, it suggests that our data on income and consumption generated by recall may be reliable enough to use in an analysis of certainty equivalence incomes.

Any comparison of estimates of poverty indices between earlier work and ours can not be made precisely because our data differs from that used in this previous work both in terms of the sample of households used and the survey period. Data in Jalan and Ravallion (1998) come from four provinces in Southern China: Guangdong, Guangxi, Guizhou, and Yunnan and cover a six year period between 1985 and 1990. Their sample covers 38,951 individuals. Data used in Li, Wang and Yue (2005), on the other hand, come from a Poverty Monitoring Survey, which covers 592 nationally designated poor counties and covers a period between 1997 and 2001. Their sample is more than 70,000 individuals. In contrast, data used here covers 8,808 households and 36,206 family members drawn from 22 provinces, and covers a period between 1998 and 2002. Our 
sample is more comparable to that used by Li, Wang and Yue (2005) than JR due to a closer matching of the time period across the two studies and the use of the same poverty lines and welfare measures (see discussion below).

When calculating poverty indices a measure defined over either income or consumption can be used. The choice of measure and the associated poverty line also is also issue so as to facilitate as close a comparison of decomposition results with a sample as possible with previous studies. Jalan and Ravallion use a consumption poverty standard employed by Chen and Ravallion (1996), involving two separate poverty lines: a lower and a higher one for each of four provinces. ${ }^{16}$ Except for a higher poverty line for Guangdong in 1990, all of the lower and higher poverty lines lie between the Chinese official poverty standard and that used by the World Bank of one dollar per day. $\mathrm{Li}$, Wang and Yue (2005) use both income and consumption as measures and employ two poverty standards, an official Chinese poverty line and the World Bank poverty line of 625 Yuan and 874 Yuan at 2000 prices. Following Li, Wang and Yue (2005), we use both income and consumption as measures and employ two poverty standards used by Chinese official agencies and the World Bank. These poverty lines in 2002 prices (rather than 2000), are 628 Yuan and 878 Yuan respectively. Both income and consumption per capita are translated into 2002 prices using provincial consumption price indices.

Table 2 reports the use of our data for both income and consumption to calculate total poverty indices and their chronic and transient components. As can be seen, total poverty based on consumption for the two given poverty lines is higher than that based on income. This reflects savings behavior by households. Using consumption as the basis for their

\footnotetext{
${ }^{16}$ Chen and Ravallion (1996) calculate a poverty line for 1988 using provincial food bundles and extend this to other years using provincial consumption price indexes. Jalan and Ravallion (1998) did not report which of their lower and higher poverty lines for each province they use when estimating poverty indexes.
} 
poverty measure, Jalan and Ravallion (1998) report $49.3 \%$ percent of poverty as transient. This lies between our estimates based on both the official poverty line and the poverty line used by the World Bank. This is broadly consistent with estimates based on our sample data reported in Table 2, even through our sample period is 10 years later than that of Jalan and Ravallion. Poverty as reported in Li, Wang and Yue (2005) is larger than in Table 2 because their study covers the poorest regions in rural China. Our shares of transient components of total poverty are below theirs for each of four cases (two poverty lines and measures), but our data may also slightly underestimate fluctuations in income and consumption over time due to the use of data based on recall.

Earlier studies of transient poverty also present indices for each of sub-group of the total sample population divided by the number of household members and educational attainment of the head of households. ${ }^{17}$ Jalan and Ravallion (1998) find that chronic poverty increases with the size of the household, while the total poverty index is Ushaped and lowest at a family size of 5 and 6. Li, Wang and Yue (2005) show similar results that lowest total poverty occurs for households with 3 family members. The upper panel of Table 3 reports results from our data that are similar to those of $\mathrm{Li}$, Wang and Yue (2005).

Both earlier studies also showed that both transient and chronic poverty indices declined with the educational level of the head of the household. The proportion of transient poverty in total poverty by these characteristics is the same in our data as in Jalan and Ravallion (1998), but there is a weaker trend with education level compared to in Li, Wang and Yue (2005). These results imply that chronic poverty declines more

\footnotetext{
${ }^{17}$ Besides the numbers of households and education of the heads of households, Jalan and Ravallion (1998) also stratify their sample by the mean yield of land and by wealth. Li, Wang and Yue (2005) also use a regional population breakdown and the age of the head of the household.
} 
quickly than transient poverty as the heads of households acquire education. Our estimates of the relationship between education level and poverty, shown in the lower panel of Table 3, are close to those of Li, Wang and Yue (2005), except for the higher education level.

In summary, calculations from our data of the relative importance of transient and chronic poverty are broadly consistent with those that of previous studies, and confirm the earlier finding that transient poverty accounts for a large proportion of total poverty. We view this rough consistency as an indication that the panel data used in our study, even though collected by recall, is appropriate to use in our analysis. 


\section{Certainty Equivalent Rural Incomes and the Urban-Rural Gap}

We now report our calculations of certainty equivalence income for the rural population for 2002 using the CHIP data described above, and the impacts these certainty equivalent incomes have on measures both the urban-rural gap and other distributional summary statistics.

Table 4 reports both summary statistics for the distribution of certainty equivalent rural income and the impacts on the measured urban-rural income gap. We report results for alternative values of $\gamma$ (the coefficient of relative risk aversion) between 0.9 and 10.0. These reflect the literature range reported on by Chetty (2003). A $\gamma$ value of 1.0 yields no well defined utility function.

We first report the mean of certainty equivalent incomes relative to the mean of observed rural incomes for 2002. With a value of 0.9 the impact of income volatility is to reduce certainty equivalent income by around 3\%, but with a $\gamma$ value of 10 certainty equivalent incomes fall by much more. We also report the standard deviation and the relative minimum and maximum incomes (1.0 as a maximum indicates no volatility). The impacts on measures of the rural income gap are reported as the far right hand side panel in Table 4. The unadjusted urban-rural income gap based on observed income is 3.245. Depending on the value of $\gamma$, the urban-rural income gap increases from 3.366 to 3.947. The Chetty (2003) preferred estimate for $\gamma$ is in the higher end of the range 0.9 to 10.0. On this basis we interpret Table 4 as suggesting that a correction for certainty equivalence of rural income in China can have the effect of increasing the urban-rural income gap by around $20 \%$. 
These results thus underscore the point that explicitly correcting rural income in China for income volatility worsens rather than ameliorates relative poverty, as uncertainty reduces the certainty equivalent value of incomes. Existing decompositions of poverty indicate that transient poverty is a significant component of poverty, pointing to poverty as a less serious problem. The results in Table 4 suggest, in contrast, that the effects of direct adjustment for volatility worsen measured inequality, and can be significant.

Table 5 report results for consumption for similar ranges of $\gamma$, using consumption rather than income data and a utility of consumption function. The impact of adjusting for certainty equivalence is more pronounced for consumption than for income, and also produces larger adjustments to the urban-rural consumption gap. These differences reflect a large number of households for whom there is greater volatility in consumption than in income in the underlying survey data. The theme of results, however, remains that volatility in the rural sector significantly increases measured inequality.

Tables 6 and 7 report comparisons of other inequality measures based on both observed and certainty equivalent income (Table 6) and observed and certainty equivalent consumption (Table 7). We report measures in both cases for certainty equivalent measures using values of $\gamma$ between 0.9 and 10.0 as before. Upper panels report the measures and the lower panel reports the impacts in relative terms of using certainty equivalent income.

Using certainty equivalent income increases all reported measures in Table 6 (the income case). The Gini coefficient increases by around 7\% using a $\gamma$ value of 10.0. This 
is a smaller increase than for the urban-rural income gap, but the Gini coefficient is known to be a relatively insensitive poverty measure.

In the case of consumption, for the coefficient of variation, the Gini coefficient, and the Theil entropy measures, measures first fall for lower values of $\gamma$ then rise with larger values of $\gamma$. This reflects the feature that the use of certainty equivalent measures has effects both across the urban-rural sub-population which serve to increase inequality, but also within the rural population. The combined effect is ambiguous. For these low values of $\gamma$ in these cases, the within rural sub-population effects dominate.

Table 8 reports Atkinson index for various combination of $\gamma$ (risk aversion) and $\varepsilon$ (social inequality aversion). We calculate the Atkinson measures both for observed income unadjusted for certainty equivalence, and for certainty equivalent income. Given social aversion to inequality of 2.0, the Atkinson index is 0.55 when observed income data used, but depending on $\gamma$ can rise to 0.78 when $\gamma$ of 10.0 . There is an approximate $20 \%$ increase in the Atkinson index to volatility. For consumption the increase is smaller.

In summary, volatility reflects a time varying income (or consumption), and with limited access to capital markets in rural areas for income (or consumption) smoothing, volatility reduces the value of the income stream relative to its certainty equivalent. Explicitly adjusting measure of household income and/or consumption for volatility using a certainty equivalent approach can increase inequality measures for China such as the urban-rural income gap by around $20 \%$. 


\section{Concluding Remarks}

Volatility of income or consumption streams has received only limited attention in the literature in terms of its impacts on relative poverty (inequality). Here we use longitudinal rural data for China between 1998 and 2002 to adjust 2002 rural income for certainty equivalence, and show that volatility in rural income worsens measures of relative poverty in China. Depending on the value used for the coefficient of relative risk aversion current estimates of the urban-rural income gap in China may need to be revised up to $20 \%$. We contrast these results to existing decompositions of poverty in China into chronic and transient components, which point to a large transient portion, with the implication that poverty viewed as a longer term problems is less serious in China than it may appear in annual data.

The central weakness in our calculations is the lack of longitudinal data on urban as well as rural income (and consumption) in China. Volatility in the urban sub-sample will lessen the effect of the adjustment we made, but it is widely believed that rural incomes are significantly more volatile than urban income. When such data becomes available a similar methodology to that we set out here can also be deployed. 


\section{Bibliography}

Alderman, Harold and Christina H. Paxson, 1994, Do the Poor Insure?: A Synthesis of the Literature on Risk and Consumption in Developing Countires, in Bacha ed. Economics in a Changing World: Volume 4: Development, Trade and the Environment, London: Macmillan Press.

Anand, Sudhir, 1983, Inequality and Poverty In Malaysia: Measurement and Decomposition, published for the World Bank, Oxford University Press.

Atkinson, Anthony B., 1975, The Economics of Inequality, Oxford: Clarendon Press.

Chen, Shaohua and Martin Ravallion, 1996, Data in Transition: Assessing Rural Living Standards in Southern China, China Economic Review, 7(1), 23-56.

Chetty Raj, 2003, A New Method of Estimating Risk Aversion, NBER working paper W9988.

Chetty Raj, 2006, A Bound on Risk Aversion Using Labor Supply Elasticities, forthcoming from American Economic Review.

Foster, J., E. Greer, J., Thorbecke, E., 1984, A Class osf decomposable poverty measures, Econometrica, 52(3), 761-766.

Jalan, J., and Ravallion, M., 1998, Transient poverty in postreform rural china, Journal of Comparative Economics, 26(2), 338-57.

Li, Shi, Pingping Wang and Ximing Yue, 2005, The Causes of Transient Poverty and its implication to Poverty Reduction Policy in Rural China, Final Report to Poverty and Economic Poverty (PEP) network, downloadable from http://www.pepnet.org/. 
Li, Shi, Chuliang Luo, Zhong Wei and Ximing Yue, 2005, The 1995 and 2002

Household Surveys: Sampling Methods and Data Description, unpublished ms.

Li, Shi and Ximing Yue, 2004, An Investigation into Urban-rural Divide in China, Caijing Magzine, March/April. (In Chinese)

Knight, John and Lina Song, 1999, The Urban-Rural Divide: Economic Disparities and Interactions in China. New York: Oxford University Press.

Morduch, Jonathan, 1995, Income Smoothing and Consumption Soothing, The Journal of Economic Perspectives, 9(3), 103-114.

Newbery, David and Joseph Stiglitz, 1981, The Theory of Commodity Price Stabilization, Oxford: Oxford University Press.

Ravallion, Martin, 1988, Expected Poverty Under Risk-Induced Welfare Variability, The Economic Journal, 98(393), 1171-1182.

Rodgers, R., Rodgers, L., 1993, Chronic poverty in the United States, The Journal of Human Resources, 28(1), 25-54.

Sicular, Terry, Ximing Yue, Bjorn Gustafsson and Shi Li, 2005, The Urban-Rural Gap and Income Inequality in China, mimeo. 
Table 1: A Comparison of Summary Statistics between CHIP and NBS Sample of Rural Income, $1998-2002^{1}$

\begin{tabular}{r|cc|c}
\hline \multirow{2}{*}{ Year } & \multicolumn{2}{|c|}{ Income } & Consumption \\
\cline { 2 - 4 } & $\begin{array}{c}\text { per capita in } \\
\text { Chinese Yuan }\end{array}$ & $\begin{array}{c}\text { Gini } \\
\text { coefficient }\end{array}$ & $\begin{array}{c}\text { Per capita in } \\
\text { Chinese Yuan }\end{array}$ \\
\hline CHIP sample & & \\
1998 & 1,983 & 0.3476 & 1,343 \\
2000 & 2,106 & 0.3471 & 1,398 \\
2001 & 2,336 & 0.3553 & 1,595 \\
2002 & 2,438 & 0.3586 & 1,682 \\
\% Change 2 & 2,605 & 0.3692 & 1,897 \\
NBS sample & 7.06 & 1.52 & 9.03 \\
1998 & 2,162 & 0.3369 & 1,590 \\
1999 & 2,210 & 0.3361 & 1,577 \\
2000 & 2,253 & 0.3536 & 1,670 \\
2001 & 2,366 & 0.3603 & 1,741 \\
2002 & 2,476 & 0.3646 & 1,834 \\
\% Change & 3.44 & 2.00 & 3.63 \\
Ratio of CHIP sample to NBS sample *100 & \\
1998 & 91.71 & 103.17 & 84.45 \\
1999 & 95.29 & 103.26 & 88.61 \\
2000 & 103.65 & 100.48 & 95.50 \\
2001 & 103.01 & 99.53 & 96.58 \\
2002 & 105.22 & 101.27 & 103.44 \\
\hline
\end{tabular}

Note: 1 See text for more details of these two samples survey sources.

2 This denotes for annual compound growth rate between 1998 and 2002 at current prices. 
Table 2: Poverty Indices and the Distribution between Chronic and Transient Poverty by Poverty Line and income/consumption Measure

\begin{tabular}{c|rrr|rrr}
\hline \multirow{2}{*}{$\begin{array}{c}\text { Poverty } \\
\text { line }\end{array}$} & \multicolumn{3}{|c|}{ Poverty index } & \multicolumn{3}{c}{ Shares of Poverty } \\
\cline { 2 - 7 } & Chronic & Transient & Total & Chronic & Transient & Total \\
\hline Income per capita & & & & \\
627.5 & 0.0013 & 0.0033 & 0.0046 & 27.33 & 72.67 & 100.00 \\
877.9 & 0.0056 & 0.0062 & 0.0118 & 47.16 & 52.84 & 100.00 \\
Consumption per capita & & & & \\
627.5 & 0.0024 & 0.0038 & 0.0063 & 38.73 & 61.27 & 100.00 \\
877.9 & 0.0122 & 0.0086 & 0.0208 & 58.69 & 41.31 & 100.00 \\
\hline
\end{tabular}

Table 3: Poverty Indices and Their Distribution by Household Characteristics

\begin{tabular}{l|ccc|ccc}
\hline \multicolumn{3}{c|}{} & \multicolumn{3}{c|}{ Poverty index } & \multicolumn{3}{c}{ Share } \\
\cline { 2 - 7 } & Chronic & Transient & Total & Chronic & Transient & Total \\
\hline \multicolumn{2}{l}{ The number of households' members } \\
1 & 0.0072 & 0.0151 & 0.0223 & 32.42 & 67.58 & 100.00 \\
2 & 0.0047 & 0.0088 & 0.0135 & 34.71 & 65.29 & 100.00 \\
3 & 0.0045 & 0.0074 & 0.0119 & 37.87 & 62.13 & 100.00 \\
4 & 0.0082 & 0.0080 & 0.0162 & 50.55 & 49.45 & 100.00 \\
5 & 0.0172 & 0.0084 & 0.0255 & 67.18 & 32.82 & 100.00 \\
6 & 0.0197 & 0.0108 & 0.0304 & 64.60 & 35.40 & 100.00 \\
7 & 0.0248 & 0.0098 & 0.0346 & 71.70 & 28.30 & 100.00 \\
8 & 0.0293 & 0.0146 & 0.0438 & 66.71 & 33.29 & 100.00 \\
The educational attainment of the heads of households & & & \\
Illiteracy and semi-illiteracy & 0.0187 & 0.0112 & 0.0300 & 62.47 & 37.53 & 100.00 \\
Primary school & 0.0155 & 0.0098 & 0.0253 & 61.34 & 38.66 & 100.00 \\
Middle school & 0.0112 & 0.0084 & 0.0196 & 57.31 & 42.69 & 100.00 \\
Higher school & 0.0076 & 0.0067 & 0.0143 & 53.35 & 46.65 & 100.00 \\
College and above & 0.0044 & 0.0024 & 0.0068 & 65.23 & 34.77 & 100.00 \\
\hline
\end{tabular}


Table 4: The Impacts of Certainty Income Equivalent Rural Income on the Urban-rural

\begin{tabular}{|c|c|c|c|c|c|c|}
\hline \multicolumn{7}{|c|}{ Income Gap } \\
\hline \multirow[t]{2}{*}{$\gamma$} & \multicolumn{4}{|c|}{$\begin{array}{l}\text { Summary statistics of the certainty } \\
\text { equivalent income scale }\left(s_{i}\right)\end{array}$} & \multicolumn{2}{|c|}{$\begin{array}{l}\text { Ratio of urban to rural per } \\
\text { capita income after adjusting } \\
\text { income for certainty } \\
\text { equivalence and relative to the } \\
\text { unadjusted ratio* }\end{array}$} \\
\hline & Mean & S.D. & Min. & Max. & After & $\begin{array}{c}\text { Index relative to } \\
\text { unadjusted ratio } \\
(100)\end{array}$ \\
\hline 0.9 & 0.9700 & 0.0496 & 0.4637 & 1.0000 & 3.3660 & 103.73 \\
\hline 1.1 & 0.9633 & 0.0606 & 0.4084 & 1.0000 & 3.3922 & 104.54 \\
\hline 2.0 & 0.9360 & 0.1028 & 0.0597 & 1.0000 & 3.4993 & 107.84 \\
\hline 4.0 & 0.8939 & 0.1458 & 0.0212 & 1.0000 & 3.6669 & 113.00 \\
\hline 5.0 & 0.8794 & 0.1556 & 0.0186 & 0.9999 & 3.7267 & 114.84 \\
\hline 6.0 & 0.8677 & 0.1622 & 0.0171 & 0.9999 & 3.7762 & 116.37 \\
\hline 8.0 & 0.8500 & 0.1704 & 0.0156 & 0.9999 & 3.8535 & 118.75 \\
\hline 10.0 & 0.8371 & 0.1750 & 0.0149 & 0.9999 & 3.9477 & 121.65 \\
\hline
\end{tabular}

Note: * the unadjusted or observed ratio of urban to rural per capita income is 3.2450.

Table 5: The Impacts of Certainty Consumption Equivalent Rural Consumption on the Urban-rural Consumption Gap

\begin{tabular}{|c|c|c|c|c|c|c|}
\hline \multirow[t]{2}{*}{$\gamma$} & \multicolumn{4}{|c|}{$\begin{array}{l}\text { Summary statistics of the certainty } \\
\text { equivalent consumption scale }\left(s_{i}\right)\end{array}$} & \multicolumn{2}{|c|}{$\begin{array}{l}\text { Ratio of urban to rural per } \\
\text { capita consumption after } \\
\text { adjusting consumption for } \\
\text { certainty equivalence and } \\
\text { relative to the unadjusted } \\
\text { ratio* }\end{array}$} \\
\hline & Mean & S.D. & Min. & Max. & After & $\begin{array}{l}\text { Index relative } \\
\text { to unadjusted } \\
\text { ratio }(100)\end{array}$ \\
\hline 0.9 & 0.9632 & 0.0577 & 0.3399 & 1.0000 & 3.4948 & 106.51 \\
\hline 1.1 & 0.9559 & 0.0674 & 0.2809 & 1.0000 & 3.5353 & 107.75 \\
\hline 2.0 & 0.9274 & 0.1004 & 0.1785 & 1.0000 & 3.6860 & 112.34 \\
\hline 4.0 & 0.8838 & 0.1361 & 0.0890 & 0.9999 & 3.8984 & 118.81 \\
\hline 5.0 & 0.8686 & 0.1451 & 0.0779 & 0.9999 & 3.9706 & 121.01 \\
\hline 6.0 & 0.8563 & 0.1514 & 0.0719 & 0.9999 & 4.0296 & 122.81 \\
\hline 8.0 & 0.8376 & 0.1591 & 0.0656 & 0.9998 & 4.1204 & 125.58 \\
\hline 10.0 & 0.8242 & 0.1634 & 0.0623 & 0.9998 & 4.1874 & 127.62 \\
\hline
\end{tabular}

Note: * the unadjusted or observed ratio of urban to rural per capita consumption is 3.2811. 
Table 6: Comparison of China-wide Inequality Measures Based on Observed and Certainty Equivalent Income

\begin{tabular}{c|cccc}
\hline$\gamma$ & $\begin{array}{c}\text { Coefficient } \\
\text { of variation }\end{array}$ & $\begin{array}{c}\text { Gini } \\
\text { coefficient }\end{array}$ & Theil index & $\begin{array}{c}\text { Mean } \\
\text { logarithmic } \\
\text { deviation }\end{array}$ \\
\hline $\begin{array}{c}\text { Observed data } \\
0.9\end{array}$ & 0.9799 & 0.4614 & 0.3620 & 0.3800 \\
1.1 & 0.9880 & 0.4651 & 0.3678 & 0.3878 \\
2.0 & 0.9902 & 0.4661 & 0.3694 & 0.3901 \\
4.0 & 1.0005 & 0.4707 & 0.3771 & 0.4020 \\
5.0 & 1.0174 & 0.4787 & 0.3904 & 0.4243 \\
6.0 & 1.0234 & 0.4816 & 0.3951 & 0.4319 \\
8.0 & 1.0283 & 0.4839 & 0.3990 & 0.4380 \\
10.0 & 1.0359 & 0.4874 & 0.4049 & 0.4472 \\
Relative measures (measure based on observed data=100) & \\
Observed data & 100.00 & 100.00 & 100.00 & 100.00 \\
0.9 & 100.82 & 100.79 & 101.60 & 102.05 \\
1.1 & 101.05 & 101.00 & 102.04 & 102.64 \\
2.0 & 102.10 & 102.01 & 104.15 & 105.79 \\
4.0 & 103.83 & 103.75 & 107.83 & 111.65 \\
5.0 & 104.44 & 104.36 & 109.14 & 113.66 \\
6.0 & 104.94 & 104.86 & 110.21 & 115.27 \\
8.0 & 105.71 & 105.62 & 111.86 & 117.68 \\
10.0 & 106.19 & 106.08 & 112.86 & 119.17 \\
\hline
\end{tabular}


Table 7: Comparison of China-wide Inequality Measures Based on Observed and Certainty Equivalent Consumption

\begin{tabular}{c|cccc}
\hline$\gamma$ & $\begin{array}{c}\text { Coefficient } \\
\text { of variation }\end{array}$ & $\begin{array}{c}\text { Gini } \\
\text { coefficient }\end{array}$ & Theil index & $\begin{array}{c}\text { Mean } \\
\text { logarithmic } \\
\text { deviation }\end{array}$ \\
\hline Observed data & 1.0662 & 0.4719 & 0.3888 & 0.3853 \\
0.9 & 1.0593 & 0.4740 & 0.3904 & 0.3896 \\
1.1 & 1.0608 & 0.4748 & 0.3917 & 0.3912 \\
2.0 & 1.0706 & 0.4791 & 0.3988 & 0.3999 \\
4.0 & 1.0896 & 0.4873 & 0.4128 & 0.4185 \\
5.0 & 1.0963 & 0.4904 & 0.4180 & 0.4256 \\
6.0 & 1.1018 & 0.4929 & 0.4223 & 0.4316 \\
8.0 & 1.1102 & 0.4967 & 0.4289 & 0.4408 \\
10.0 & 1.1163 & 0.4995 & 0.4337 & 0.4475 \\
Relative measures $($ measure based on observed data=100) & \\
Observed data & 100.00 & 100.00 & 100.00 & 100.00 \\
0.9 & 99.36 & 100.44 & 100.40 & 101.11 \\
1.1 & 99.49 & 100.61 & 100.73 & 101.53 \\
2.0 & 100.42 & 101.51 & 102.56 & 103.81 \\
4.0 & 102.19 & 103.26 & 106.16 & 108.61 \\
5.0 & 102.83 & 103.91 & 107.50 & 110.47 \\
6.0 & 103.34 & 104.43 & 108.61 & 112.02 \\
8.0 & 104.13 & 105.24 & 110.31 & 114.41 \\
10.0 & 104.70 & 105.83 & 111.55 & 116.15 \\
\hline
\end{tabular}


Table 8: Atkinson indices of inequality of both observed and certainty equivalent income and consumption

\begin{tabular}{c|ccccccccc}
\hline \multicolumn{1}{c}{$\gamma$} & $\begin{array}{c}\text { Observed } \\
\text { data }\end{array}$ & 0.9 & 1.1 & 2.0 & 4.0 & 5.0 & 6.0 & 8.0 & 10.0 \\
\hline $\begin{array}{c}\text { Income } \\
0.9\end{array}$ & 0.2889 & 0.2937 & 0.2951 & 0.3022 & 0.3152 & 0.3197 & 0.3232 & 0.3286 & 0.3318 \\
1.1 & 0.3424 & 0.3482 & 0.3499 & 0.3590 & 0.3756 & 0.3812 & 0.3855 & 0.3920 & 0.3959 \\
2.0 & 0.5452 & 0.5603 & 0.5674 & 0.6377 & 0.7340 & 0.7505 & 0.7608 & 0.7727 & 0.7791 \\
4.0 & 0.9191 & 0.9497 & 0.9623 & 0.9934 & 0.9976 & 0.9979 & 0.9981 & 0.9982 & 0.9983 \\
5.0 & 0.9600 & 0.9758 & 0.9821 & 0.9969 & 0.9989 & 0.9990 & 0.9991 & 0.9992 & 0.9992 \\
6.0 & 0.9744 & 0.9846 & 0.9887 & 0.9981 & 0.9993 & 0.9994 & 0.9994 & 0.9995 & 0.9995 \\
8.0 & 0.9848 & 0.9909 & 0.9933 & 0.9989 & 0.9996 & 0.9996 & 0.9997 & 0.9997 & 0.9997 \\
10.0 & 0.9886 & 0.9932 & 0.9950 & 0.9992 & 0.9997 & 0.9997 & 0.9997 & 0.9998 & 0.9998 \\
Consumption & & & & & & & & & \\
0.9 & 0.2940 & 0.2966 & 0.2976 & 0.3030 & 0.3143 & 0.3186 & 0.3222 & 0.3277 & 0.3316 \\
1.1 & 0.3442 & 0.3474 & 0.3486 & 0.3549 & 0.3681 & 0.3732 & 0.3774 & 0.3838 & 0.3884 \\
2.0 & 0.5116 & 0.5164 & 0.5181 & 0.5275 & 0.5477 & 0.5554 & 0.5616 & 0.5708 & 0.5772 \\
4.0 & 0.6848 & 0.6931 & 0.6972 & 0.7406 & 0.8098 & 0.8217 & 0.8290 & 0.8375 & 0.8424 \\
5.0 & 0.7300 & 0.7413 & 0.7488 & 0.8316 & 0.8962 & 0.9036 & 0.9078 & 0.9124 & 0.9150 \\
6.0 & 0.7640 & 0.7788 & 0.7910 & 0.8870 & 0.9329 & 0.9377 & 0.9404 & 0.9433 & 0.9449 \\
8.0 & 0.8122 & 0.8321 & 0.8510 & 0.9320 & 0.9599 & 0.9627 & 0.9643 & 0.9661 & 0.9670 \\
10.0 & 0.8433 & 0.8644 & 0.8839 & 0.9489 & 0.9699 & 0.9720 & 0.9732 & 0.9745 & 0.9752 \\
\hline
\end{tabular}

